\title{
Clinical Studies on the Acid-Base Balance Disturbance in Congestive Heart Failure
}

\author{
Masaaki Awamura
}

This paper will discuss the disturbances in acid-base regulation that occurs in congestive heart failure. The study consists of four parts.

1) The $\mathrm{pH}, \mathrm{Pco}_{2}, \mathrm{Po}_{2}$, and $\left[\mathrm{HCO}_{3}{ }^{-}\right]$of arterial blood and serum electrolytes in congestive heart failure.

2) Serial studies of the acid-base balance disturbance in some patients treated with digitalis and diuretics.

3) Short-term experiments in which patients were treated with digitalis or diuretic for a week or so.

4) The effect of efficacious diuretic furosemide upon the acid-base balance.

$\mathrm{M}^{\wedge}$ ANY studies have been reported on the disturbance of the acid-base regulation. But in clinical circles in the subject does not appear to have been fully appreciated. This might have been due to a confusing terminology and methodology.

However, at present, accurate and simple methods have been developed for $\mathrm{pH}$ measurement.

This paper will discuss the disturbances in the acid-base regulation that occur in congestive heart failure. The object of the study is to observe the incidence, development and severity of the acid-base balance disturbance during the treatment and to study the mechanism of these changes.

The study consists of four parts.

1) The $\mathrm{pH}, \mathrm{PCO}_{2}, \mathrm{Po}_{2}$ and bicarbonate concentration of arterial blood and serum electrolytes in congestive heart failure, and correlations between pairs of them.

2) Serial studies of the acid-bace balance disturbance in some patients treated with digitalis or diuretics.

Case 1 was designed to elucidate the incidence and severity of alkalosis during the diuretic therapy with trichloromethiazide.
Case 2 was designed to investigate to what extent spironolactone could prevent alkalosis and hy pokalaemia during continuous administration of furosemide.

Case 3 was designed to observe the effect of increased aldosterone secretion, so-called rebound phenomenon, on the acid-base balance during and after diuretic therapy.

3) Short-term experiments in which patients were treated with digitalis or diuretic for a week or so.

The tendency to induce acid-base balance disturbance and the alteration in serum electrolytes were studied.

4) The effect of efficacious diuretic furosemide which has a very rapid onset and is no carbonic anhydrase inhibitor, upon the acidbase balance was studied. In a small group of patients urinary excretion of aldosterone was determined. The purpose of this experimental set-up was to avoid marked variations in the long-term experiments.

\section{Materials}

The material comprises 79 adult patients with congestive heart failure without history or clinical evidence of pulmonary disorder.

\footnotetext{
The 3rd Division, Department of Internal Medicine, Faculty of Medicine, Kyoto University, Kyoto

(Director: Prof. M. Takayasu)
} 
Aetiological classification is shown in Table I and age \& sex distribution in Table II.

Patients were selected to represent mild, moderately severe and late resistant cases. Functional classiflcation follow the Criteria Committee of the New York Heart Association.

Dietary intake of sodium chloride was, as a rule, $5 \mathrm{~g}$ a day in class 2 to 4 decompensation.

Table I Aetiological Classification of Toral Cases

\begin{tabular}{lc}
\hline Hypertensive Heart Disease & 13 \\
Mitral Valvular Disease & 38 \\
Aortic Valvular Disease & 7 \\
Combined Valvular Disease & 21 \\
\hline
\end{tabular}

Table II Age and Sex Distribution of Total, Cases

\begin{tabular}{lcc}
\hline & Male & Female \\
\hline Over 70 yrs. & 1 & 1 \\
$60 \ldots . .69$ yrs. & 4 & 2 \\
$50 \ldots . .59$ yrs. & 5 & 7 \\
$40 \ldots . .49$ yrs. & 5 & 8 \\
$30 \ldots . .39$ yrs. & 8 & 9 \\
$20 \ldots . .29$ yrs. & 14 & 12 \\
$10 \ldots . .19$ yrs. & 1 & 2 \\
\hline
\end{tabular}

\section{Methods}

In all instances the arterial blood was drawn by percutaneous puncture of radial or femoral artery. The blood would flow by itself into the syringe in which a few drops of heparin solution had been sucked in advance, under strictly anaerobic condition.
The various determinations were made within fifteen minutes following the removal of blood.

The $\mathrm{pH}$, the partial pressure of carbon dioxide and the partial pressure of oxygen of arterial whole blood were determined by means of a IL-113 pH/ Gas Analyser in a water bath thermostated at $37^{\circ} \mathrm{C}$. Plasma bicarbonate concentoration was calculated by the Henderson-Hasselbalch equation. The constants used for the calculation are $\mathrm{pK}=6.11$ and $\mathrm{S}=0.0306^{1}$.

Serum and urinary sodium, potassium and chloride were determined by flame photometry, using a Baird flame photometer.

Urinary excretion of aldosterone was measured by KUBO \& NISHIDA ${ }^{21,24}$ according to the double isotope derivative method of Kliman \& Peterson.

\section{RESUlts}

I (1) Fig. 1 gives the distribution of $\mathrm{pH}$ in all 79 patients who are divided into three groups according to the medication. In some cases $\mathrm{pH}$ was measured two or three times.

It is seen that in patients treated with digitalis alone the $\mathrm{pH}$ is normal in the great majority of cases and in a few cases has the tendency to shift toward the alkaline side. But there is no difference between the degree of decompensation and $\mathrm{pH}$. Half of the patients treated with digitalis and benzothiadiazine show the apparent elevation in $\mathrm{pH}(7.450-7.525)$.

The $\mathrm{PCO}_{2}$ and the bicarbonate concentration are shown in Fig. $2 \& 3$. The bicarbonate concentration was derived by calculation. About one third of the patients received digitalis show the rise in $\mathrm{Pco}_{2}(45-55 \mathrm{mmHg})$, but the pa-

\section{PH}

(1)

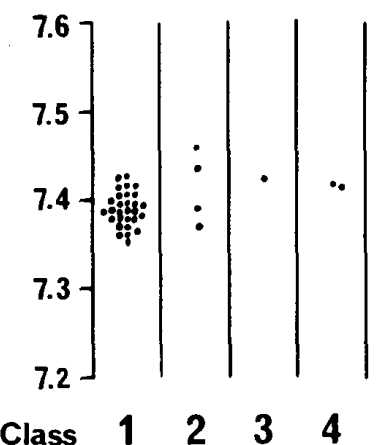

(2)

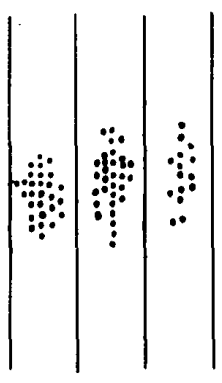

(3)

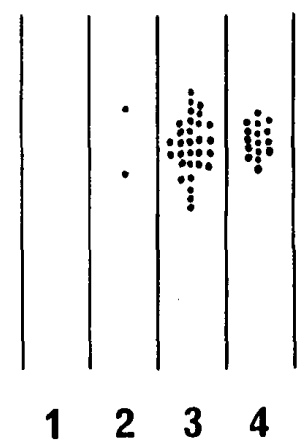

Fig. 1. $\mathrm{pH}$ values in the patients with cardiac failure.

(1) received no medication

(2) treated with digitalis

(3) treated with digitalis and benzothiadiazine diuretics

Japanese Circulation Journal Vol. 33, March 1969 
tients received combined treatment show the normal values in most cases.

The bicarbonate concentration values cover a wide range, but in the combined treatment they have the tendency to rise compared with digitalis cases.

(2) Fig. 4 shows schematically the relationship between $\mathrm{pH}, \mathrm{PCO}_{2}$ and bicarbonate concentration. The pattern of the acid-base balance disturbance can be identified from the figure.

It is evident that the patients treated with diuretics are grouped predominantly in the area 1 or 2 . In area 1 , the points lie above normal buffer line and to the left of normal $\mathrm{PCO}_{2}$ isobar and because they are right of normal $\mathrm{pH}$ range, they represent partially compensated metabolic alkalosis. In area 2, the points lie to the right of normal $\mathrm{PCO}_{2}$ isobar and above normal buffer line. They represent the combination of respiratory and metabolic alkalosis.

Patients treated with digitalis alone are more scattered in the normal $\mathrm{pH}$ range, but grouped mainly near the area 1,3 and 4 . Area 3 symbolizes partially compensated respiratory acidosis and area 4 means partially compensated respiratory alkalosis.

(3) In Fig. 5 arterial $\mathrm{PCO}_{2}$ is plotted on the abscissa and bicarbonate on the ordinate. According to the medication, the patients are divided into two groups (treated with digitalis and treated with digitalis \& diuretics).

Two observations are noteworthy. Firstly, there is a linear relationship between $\mathrm{PCO}_{2}$ and bicarbonate concentration. Secondly, the slope

\section{$\mathrm{PCO}_{2}$ \\ $\mathrm{mmHg}$}

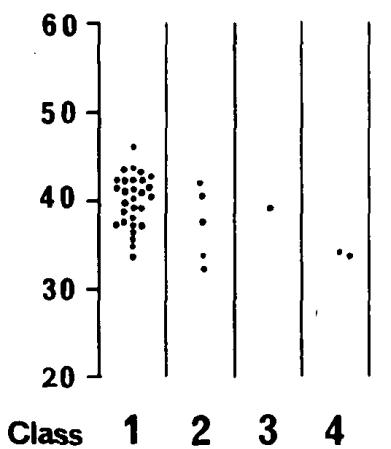

(2)

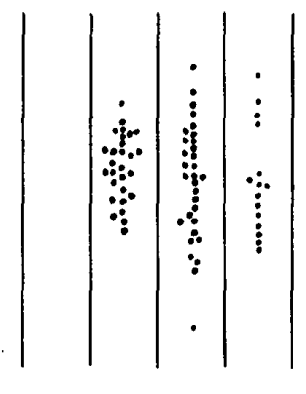

(3)

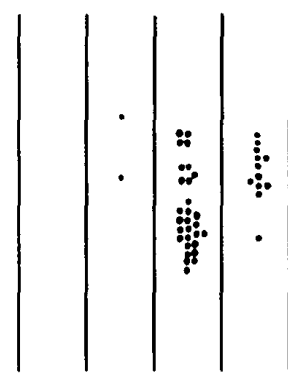

$\begin{array}{llll}1 & 2 & 3 & 4\end{array}$

Fig. 2. $\mathrm{P}_{\mathrm{CO} 2}$ values in the patients with cardiac failure.

(1) received no medication

(2) treated with digitalis

(3) treated with digitalis and benzothiadiazine diuretics

\section{$\mathrm{HCO}_{3}^{-}$}

$\mathrm{mEq} / \mathrm{L} \quad(1)$

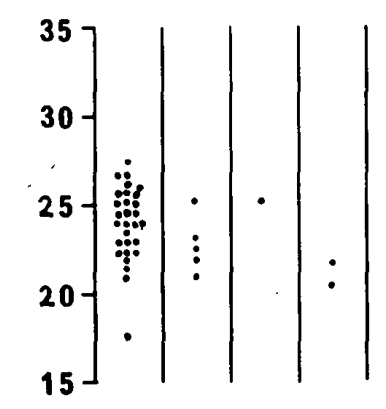

(2)

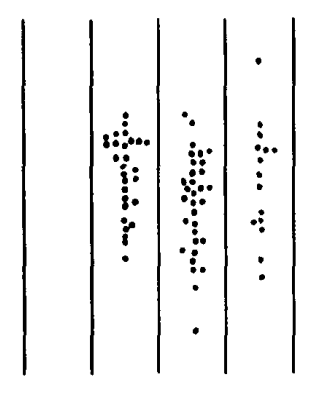

(3)

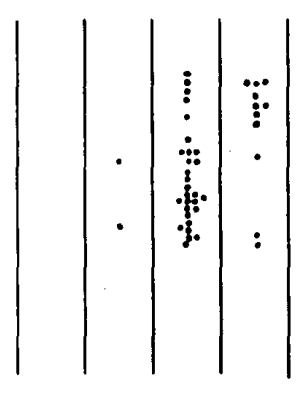

$\begin{array}{llll}1 & 2 & 3 & 4\end{array}$

Class $\begin{array}{llll}1 & 2 & 3 & 4\end{array}$

$\begin{array}{llll}1 & 2 & 3 & 4\end{array}$

ac failure.

(1) received no medication

(2) treated with digitalis

(3) treated with digitalis and benzothiadiazine diuretics 
which is drawn by inspection through the average points of group 2 is more steeper than of group 1.

(4) Reduced arterial $\mathrm{PCO}_{2}$ and the use of oral diuretics in decompensated cardiac patients will result in metabolic or/and respiratory alkalosis and numerous observations have confirmed the inverse relationship between serum potassium level and extracellular $\mathrm{pH}^{2,3}$. But in the present study no correlation was found between $\mathrm{pH}$ and serum potassium (Fig. 6). The serum potassium even increased in the presence of alkalosis and no significant hypokalaemia could be found.

(5) The relationship between $\mathrm{PCO}_{2}$ and $\mathrm{Po}_{2}$ is presented in Fig. 7. It includes the patients with cardiac decompensation and without any clinical evidence of pulmonary disorder.

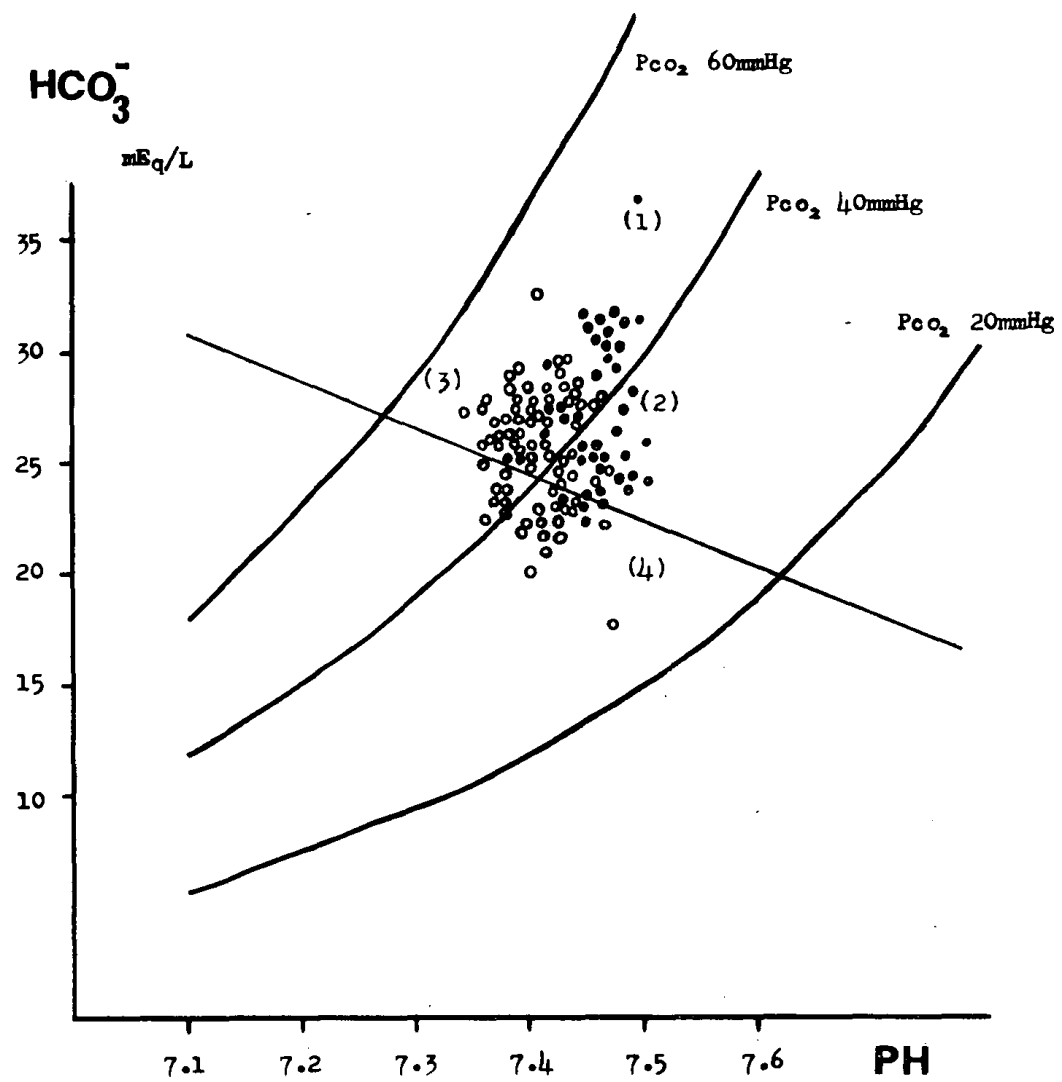

Fig. 4. Relationship between arterial $\mathrm{pH}, \mathrm{P}_{\mathrm{CO}}$, and $\mathrm{HCO}_{3}^{-}$concentration in the patients with cardiac failure.

The closed circles depict the patients with digitalis $\&$ diuretics and the open the patients with digitalis.
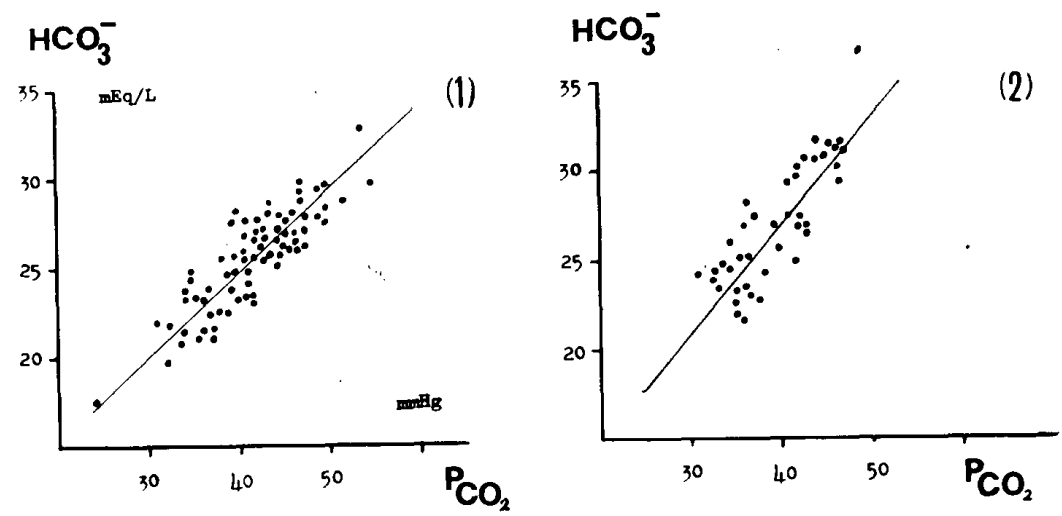

Fig. 5. Relationship between arterial $\mathrm{PCO}_{2}$ and $\mathrm{HCO}^{-}$concentration in the cardiac patients (1) treated with digitalis (2) treated with digitalis and diuretics. 


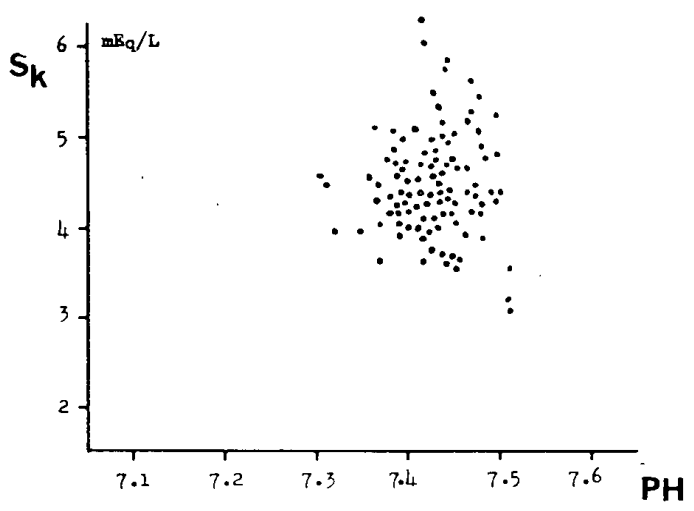

Fig. 6. Relationship between arterial pH and serum potassium in the patients with cardiac failure.

It is evident that most patients are grouped in the area of normal or near-normal $\mathrm{PCO}_{2}$ and $\mathrm{Po}_{2}$. In pulmonary disease the increase in $\mathrm{PCO}_{2}$ is always accompanied by the reduction in $\mathrm{Po}_{2}$, and the pattern is entirely different.

II In the next place, some case reports will be presented.

Case 1 (Fig. 8) A 60 year-old male had class

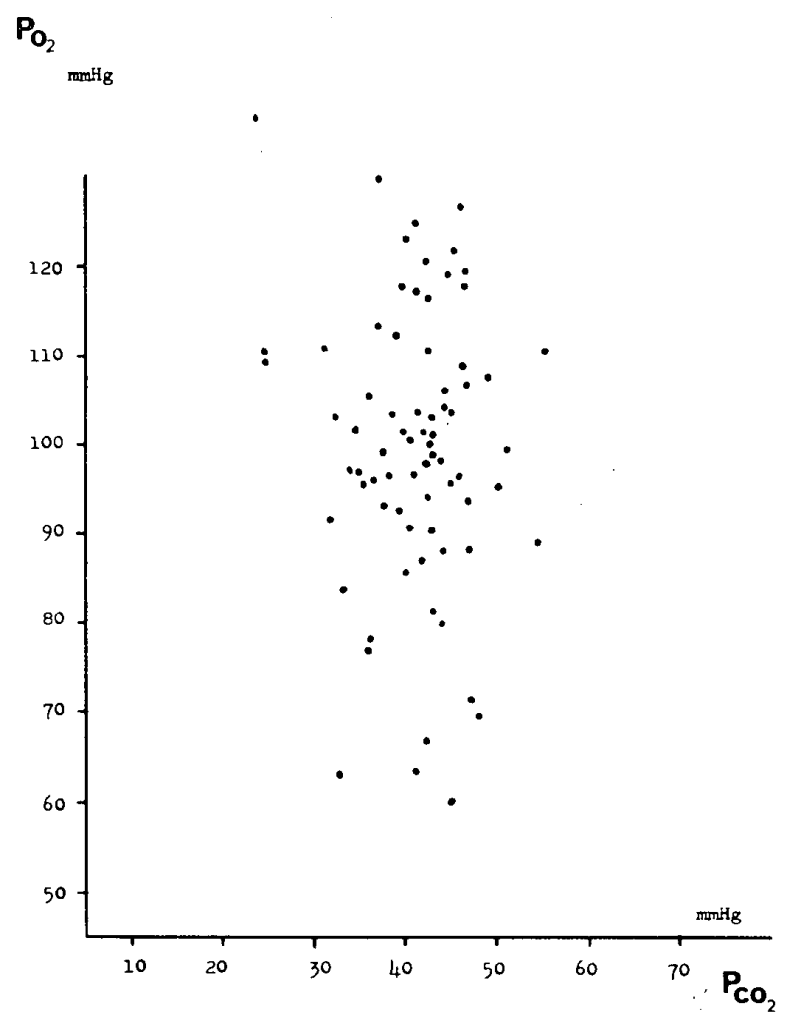

Fig. 7. Relationship between arterial $\mathrm{P}_{\mathrm{CO} 2}$ and $\mathrm{P}_{\mathrm{O} 2}$.
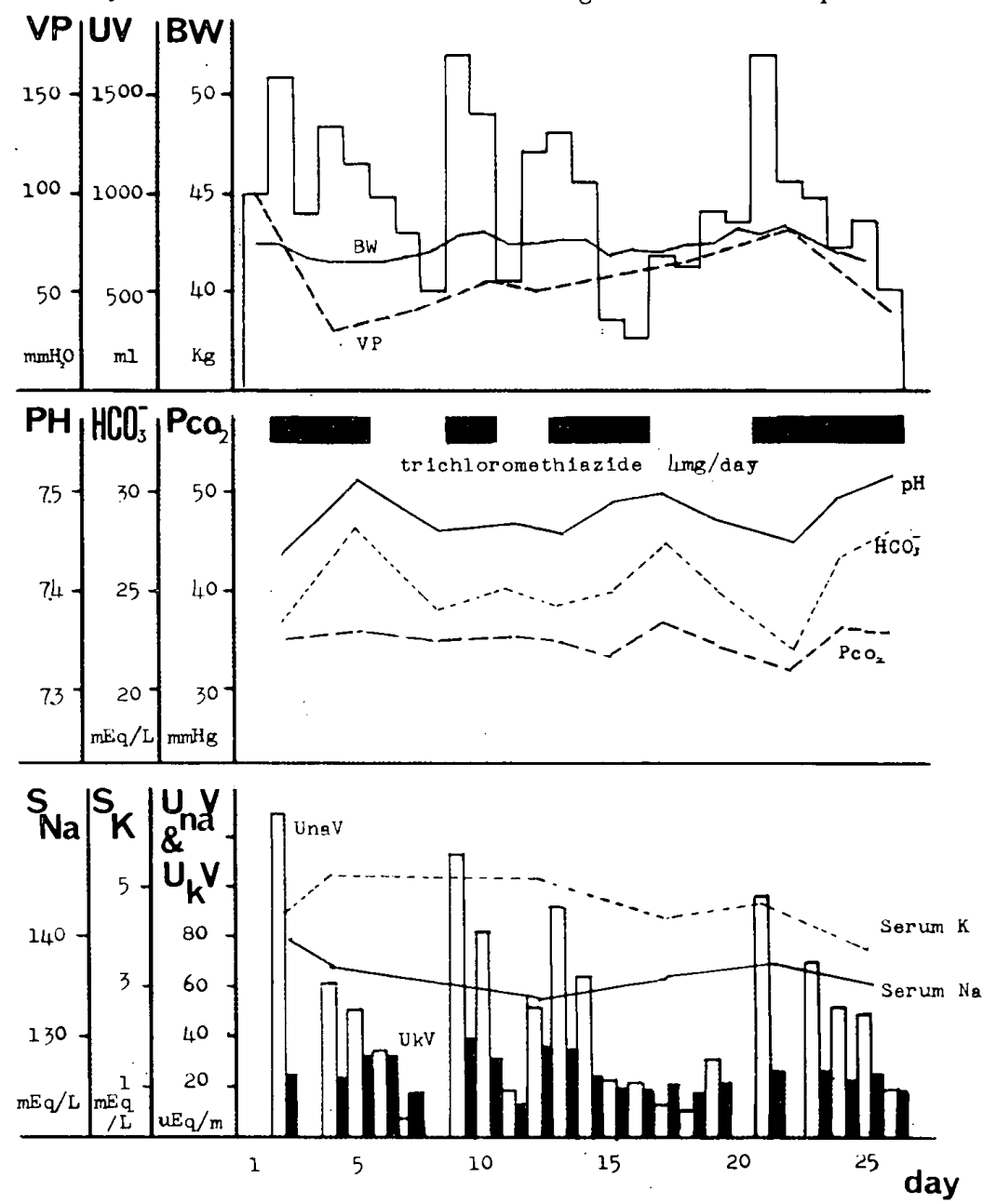

Fig. 8. Case 1 Effect of trichloromethiazide on acid-base balance and serum \& urinary electrolytes. 
4 decompensation and mitral disease. Dietary sodium chloride intake was $5 \mathrm{~g}$ and oxygen tent was applied for two weeks.

During treatment with maintenance doses of digoxin $(0.375 \mathrm{mg})$ which already instituted, trichloromethiazide was administered orally in doses of $4 \mathrm{mg}$ a day.

To study the effect of the diuretic on the acid-base balance, a few days treatment were altered with a few days without treatment. When trichloromethiazide was given there was a considerable and progressive rise in $\mathrm{pH}$. $\mathrm{PCO}_{2}$ remained unchanged in the low normal range, but bicarbonate rose from an initial value in the low normal range to an ultimate value in the high normal range so that $\mathrm{pH}$ shifted toward the alkaline side. On stopping the diuretic there was a reduction in $\mathrm{pH}$ and bicarbonate.
On the first day that the drug was given the subject showed a great increase in water and sodium excretion, but potassium excretion was only slightly enhanced. On the subsequent days sodium excretion fell to the level similar to that seen before the diuretic was given, but potassium excretion remained slightly elevated. Serum sodium remained in the subnormal or low normal range throughout the treatment, whereas serum potassium showed high level for two weeks then decreased to the low normal range.

Case 2 (Fig. 9) A 35 year-old male had class 3 to 4 decompensation, combined valvular disease and VSD. Dietary intake of sodium chloride was $5 \mathrm{~g}$ a day. During the treatment with maintenance doses of furosemide ( $40 \mathrm{mg}$ ), spironolactone was administered in doses of 50

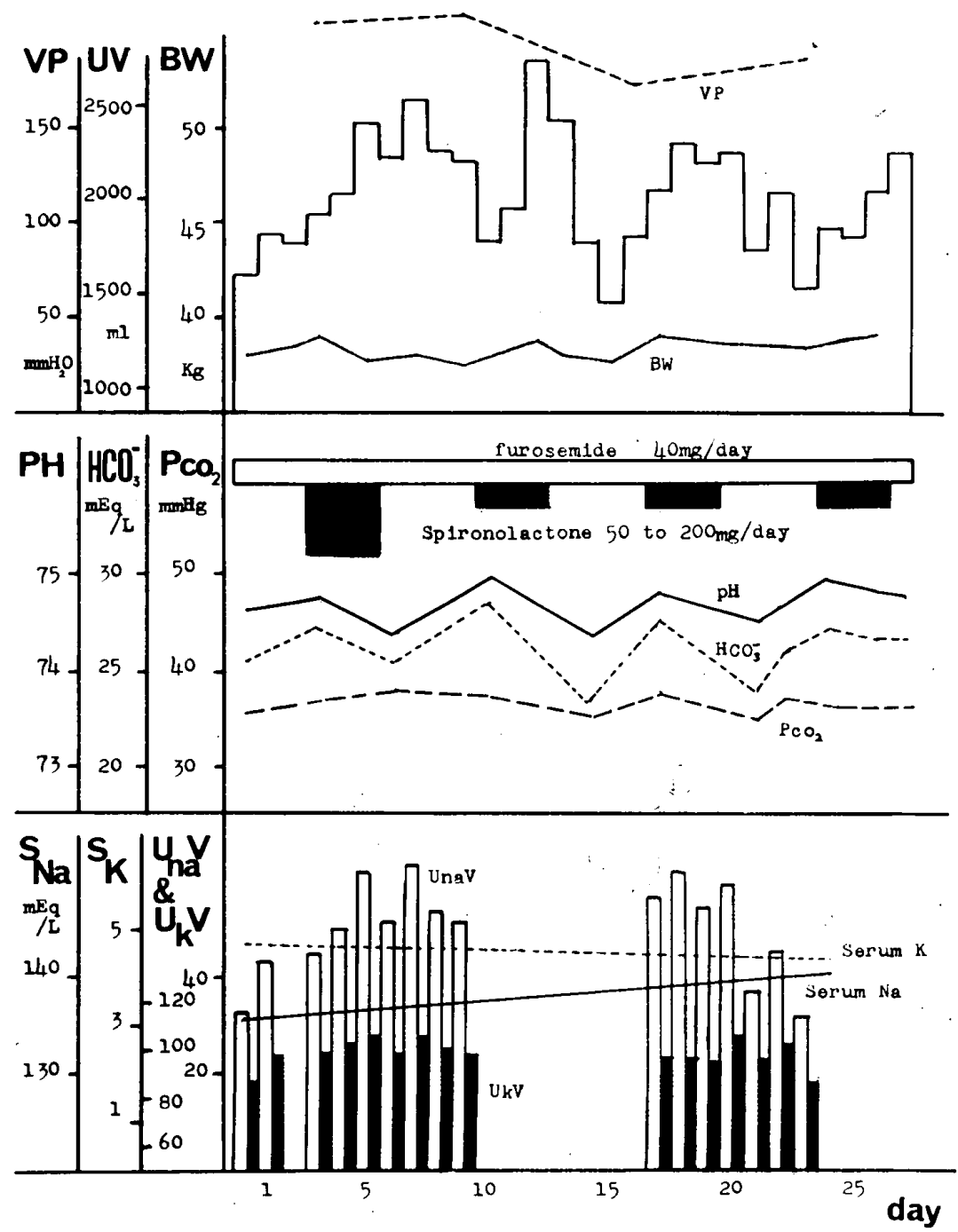

Fig. 9. Case 2 Effect of furosemide and spironolactone on acide-base balance and serum \& urinary electrolytes. 
$\mathrm{mg}$ to $200 \mathrm{mg}$ at four-day intervals. $\mathrm{pH}$ and bicarbonate concentration rose when furosemide was given and fell when spironolactone was added. Respiratory compensation for these changes was relatively ineffective. Urinary sodium excretion increased when spironolactone was added, but urinary potassium excretion was little altered.

Case 3 (Fig. 10) A 52 year-old female had class 2 decompensation and myocardiopathy. Dietary sodium chloride intake was $5 \mathrm{~g}$. During the treatment with maintenance doses of lanatoside $\mathrm{C}(0.2 \mathrm{mg}$ intravenously), trichloromethiazide $(4 \mathrm{mg})$ and spironolactone $(100 \mathrm{mg})$ were administered orally as shown in Fig. 10. $\mathrm{pH}, \mathrm{PCO}_{2}$ and bicarbonate rose progressively when trichloromethiazide was given and returned to the initial level after withdrawal of the drug. During the administration of spiro- nolactone they remained unchanged. On stopping the diuretics a marked increase in bicarbonate concentration and a compensatory increase in $\mathrm{PCO}_{2}$ occurred transiently. Then $\mathrm{pH}$, $\mathrm{PCO}_{2}$ and bicarbonate concentration returned to normal. When spironolactone was given to the subject there was a great rise in urinary sodium excretion on the 4 th day. The rise in potassium excretion was smaller than that observed when trichloromethiazide was given. A fall in serum sodium occurred during the administration of spironolactone, but serum potassium remained in normal range through the course.

III (1) Effects of short-term treatment with benzothiadiazine derivatives upon acid-base balance and serum electrolytes (Fig. $11 \&$ Table III)

The oral diuretics of the benzothiadiazine

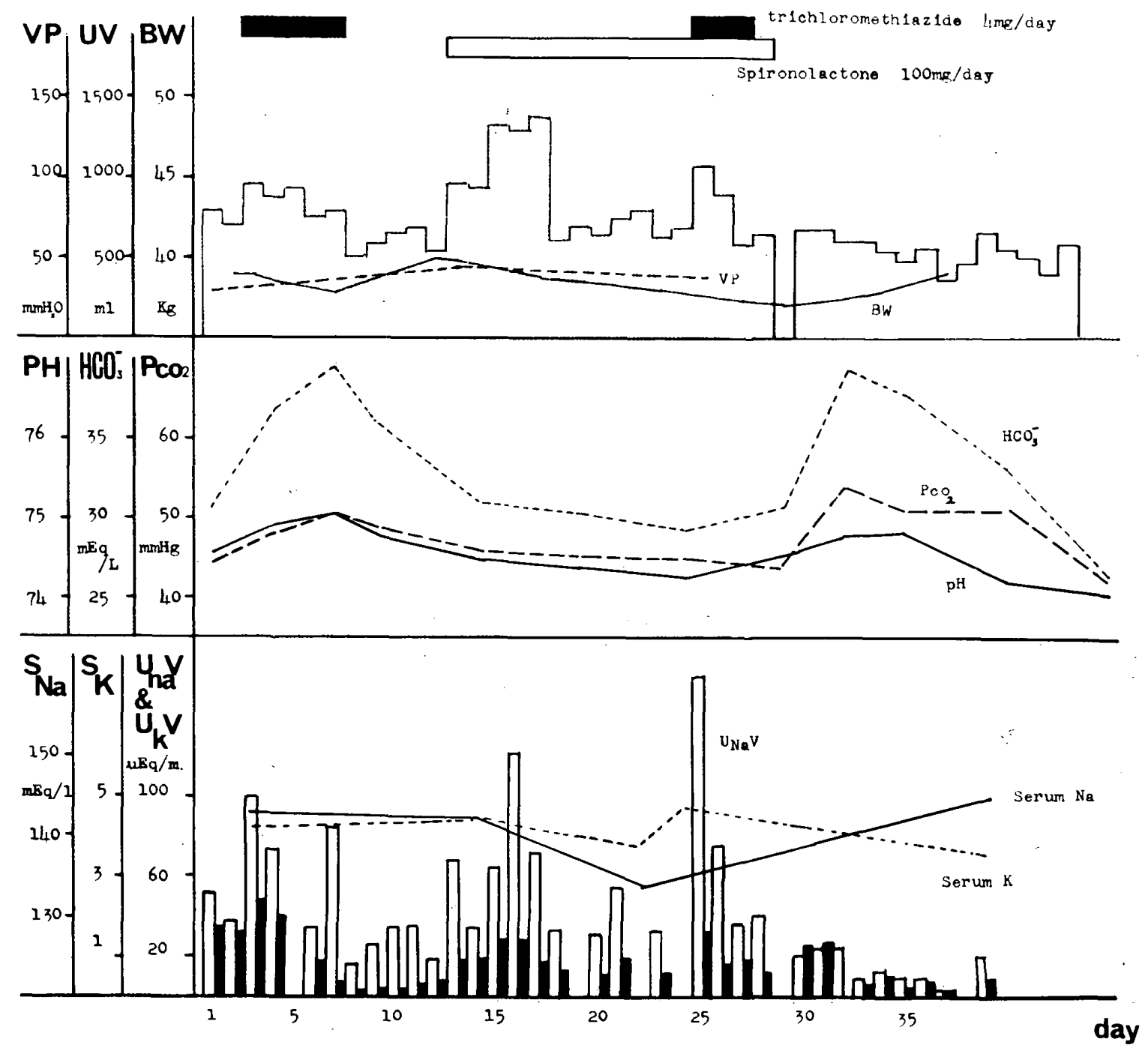

Fig. 10. Case 3 Effect of increased aldosterone secretion on acid-base balance. 
group have been coming into the increasing clinical use in recent years.

The object of this short-term experiment was to elucidate the severity of acid-base balance and serum electrolyte disturbance.

The material comprised ten adult patients with congestive heart failure. The treatment consisted in oral administration of trichloromethiazide $4 \mathrm{mg}$ a day in most cases. The majority of patients had been received digitalis and $5 \mathrm{~g} \mathrm{NaCl}$ a day.

The experiment was instituted by the observation period of two or three days and continued by one week's medication. Arterial $\mathrm{pH}, \mathrm{PCO}_{2}$, bicarbonate and serum electrolytes were determined before and during the experimental period.

The patients showed marked increase in bicarbonate concentration corresponding to the decrease in serum chloride. But $\mathrm{PCO}_{2}$ showed

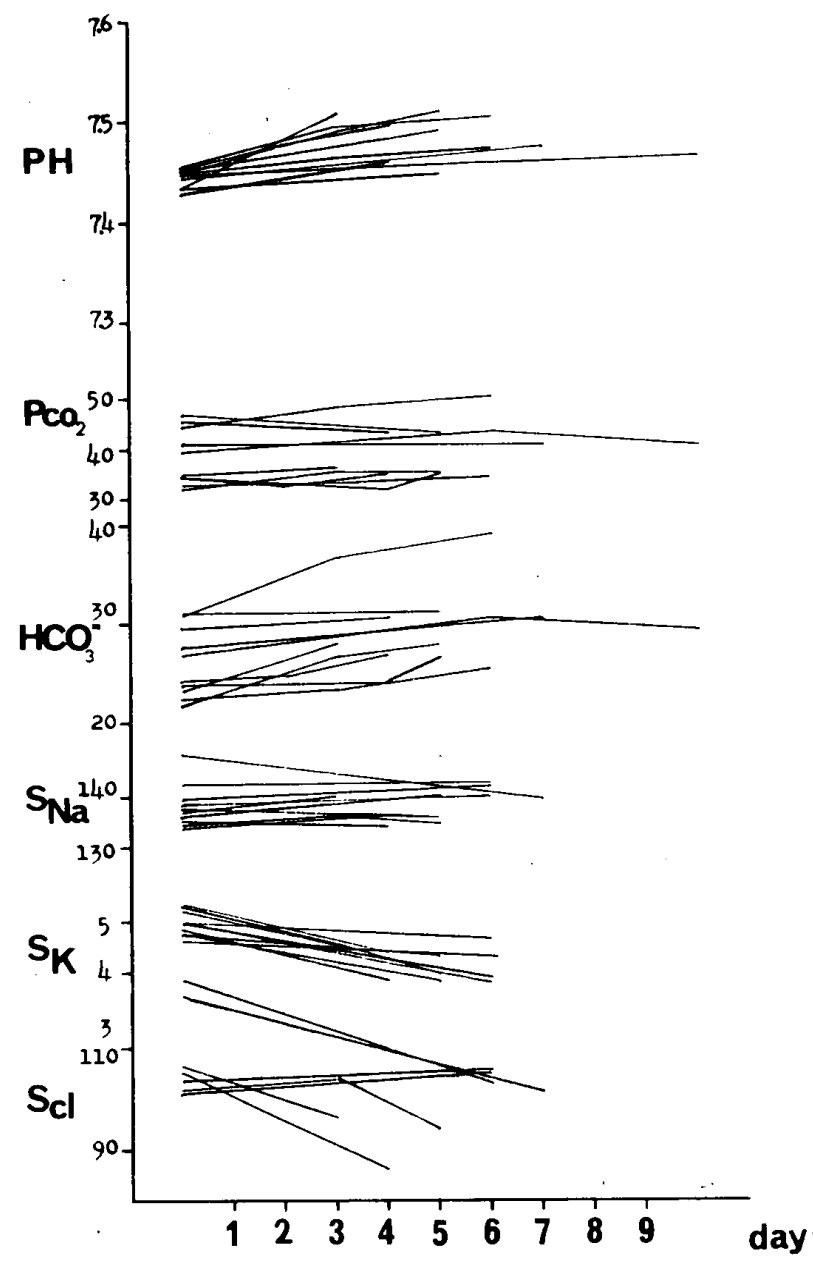

Fig. 11. Changes in $\mathrm{pH}, \mathrm{P}_{\mathrm{CO}}, \mathrm{HCO}_{3}^{-}$and serum electrolytes caused by the oral administration of benzothiadiazine diuretics.
Table III Changes in PH, $\mathrm{P}_{\mathrm{CO} 2}, \mathrm{HCO}^{-}{ }_{3}$ and Serum Electrolytes Caused by the Oral Administration of Benzothiadiazine DiURETICS

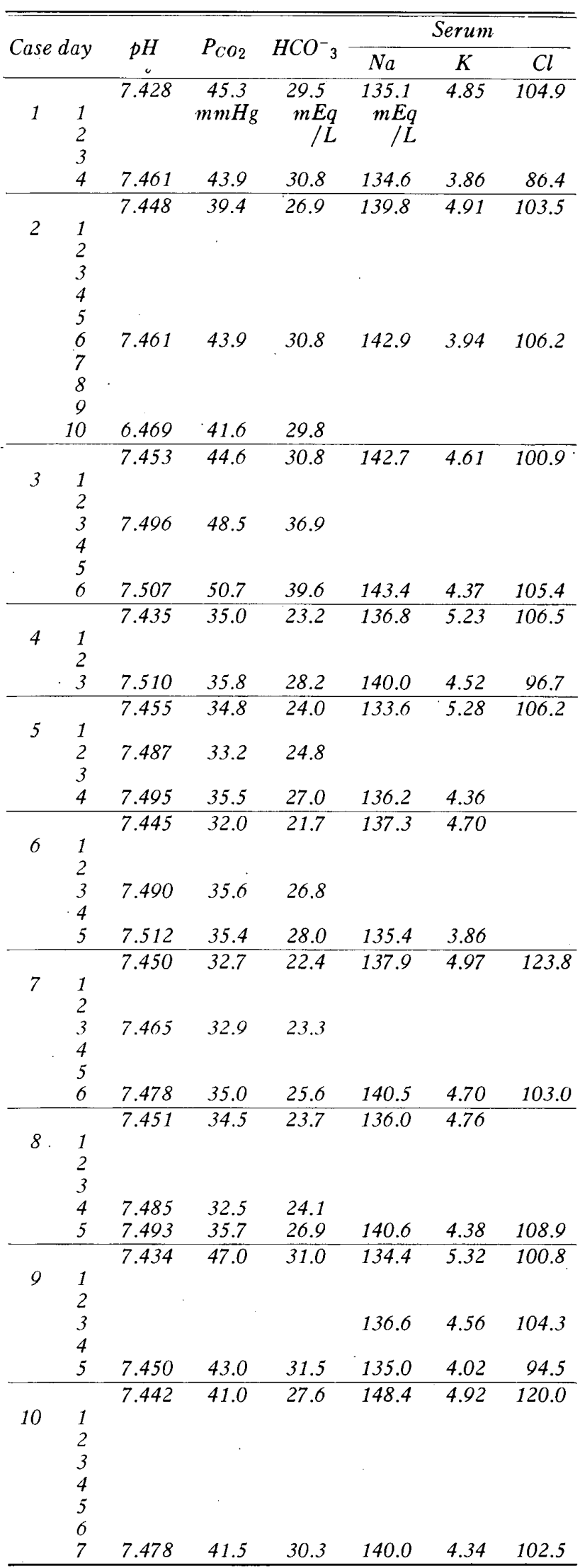

Japanese Circulation Journal Vol. 33, Marc'́ 1969 
essentially no change. Subsequently $\mathrm{pH}$ shifted toward the alkaline side. Serum sodium remained unchanged or moderately decreased, while a considerable fall in serum potassium occurred after one week's treatment.

(2) Effects of acute digitalisation upon acidbase balance and serum electrolytes (Fig. $12 \&$ Table IV)

The present study describes the type of response encountered when lanatoside $C$ was administered intravenously. All four patients had class 4 decompensation and were on the low salt diet ( $5 \mathrm{~g} \mathrm{NaCl}$ daily). Oxygen tents had been applied.

Arterial $\mathrm{pH}, \mathrm{P}_{\mathrm{CO} 2}$, bicarbonate and serum electrolytes were determined before any treatment was given, then patients were saturated with lanatoside $\mathrm{C}$ in one or two days.

$\mathrm{P}_{\mathrm{CO} 2}$ was in normal or subnormal range before the treatment, which is characteristic of dyspnoeic patient in heart failure, then rose

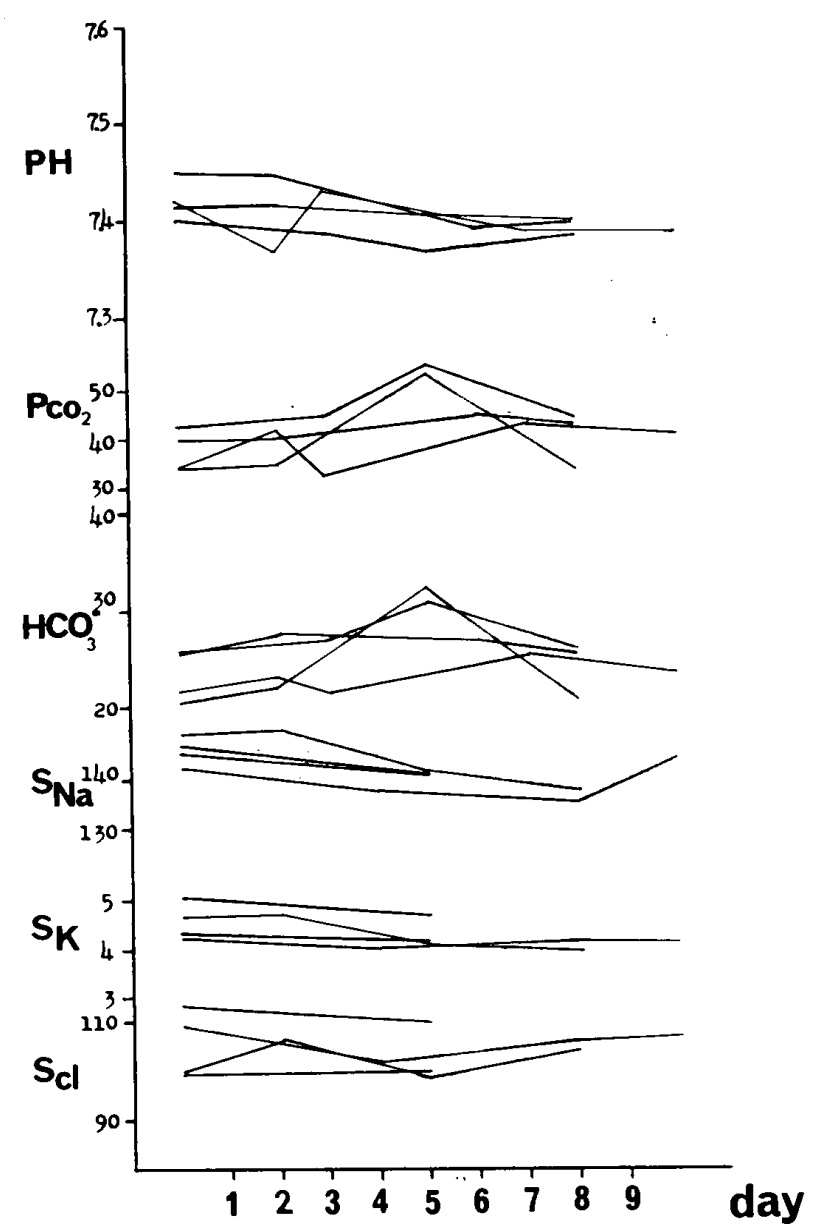

Fig. 12. Changes in $\mathrm{pH}, \mathrm{P}_{\mathrm{CO} 2}, \mathrm{HCO}^{-}{ }_{3}$ and serum electrolytes caused by the intravenous administration of lanatoside $\mathrm{C}$. gradually and reached the peak within five or seven days. Thereafter it showed the tendency to return to initial level. The changes in bicarbonate concentration were in parallel with that in $\mathrm{P}_{\mathrm{CO} 2}$, but the compensation was incomplete and $\mathrm{pH}$ shifted consequently from upper normal range into lower normal range.

Serum sodium and potassium were slightly depressed during the entire period.

Table IV Changes in PH, $\mathrm{P}_{\mathrm{CO} 2}, \mathrm{HCO}^{-}{ }_{3}$ and Serum Electrolytes Caused by the Intravenous Administration of Lanatoside C

\begin{tabular}{|c|c|c|c|c|c|c|c|}
\hline \multirow{2}{*}{\multicolumn{2}{|c|}{ Case day }} & \multirow{2}{*}{$p \mathrm{H}$} & \multirow{2}{*}{$P_{\mathrm{CO}_{2}}$} & \multirow{2}{*}{$\mathrm{HCO}^{-}{ }_{3}$} & \multicolumn{3}{|c|}{ Serum } \\
\hline & & & & & $\mathrm{Na}$ & $K$ & $\mathrm{Cl}$ \\
\hline \multirow{8}{*}{1} & & 7.419 & 34.2 & 21.9 & 142.2 & 4.22 & 109.4 \\
\hline & $\begin{array}{l}1 \\
2\end{array}$ & 7 & $m m H g$ & $m E q / L$ & & & \\
\hline & 3 & $\begin{array}{l}1.504 \\
7.428\end{array}$ & $\begin{array}{l}41.0 \\
33.4\end{array}$ & 21.3 & & & \\
\hline & 4 & & & & 137.6 & 4.00 & 101.5 \\
\hline & 5 & & & & & & \\
\hline & $\begin{array}{l}6 \\
7\end{array}$ & 7.391 & 42.5 & 25.4 & & & \\
\hline & $\begin{array}{l}8 \\
9\end{array}$ & & & & 135.4 & 4.12 & 106.1 \\
\hline & 10 & 7.383 & 40.5 & 23.6 & 144.5 & 4.14 & 107.1 \\
\hline \multirow{7}{*}{2} & & 7.400 & 42.5 & 25.9 & 145.5 & 5.08 & 99.2 \\
\hline & $\begin{array}{l}1 \\
2\end{array}$ & & & & & & \\
\hline & 3 & 7.386 & 45.9 & 27.0 & & & \\
\hline & 5 & 7.364 & 55.3 & 31.0 & 141.7 & 4.71 & 100.0 \\
\hline & 6 & & & & & & \\
\hline & 7 & & & & & & \\
\hline & 8 & 7.385 & 44.5 & 26.2 & & & \\
\hline \multirow{8}{*}{3} & & 7.413 & 33.7 & 20.6 & 149.6 & 4.68 & 99.3 \\
\hline & 1 & & & & & & \\
\hline & $\begin{array}{l}2 \\
3\end{array}$ & 7.415 & 35.0 & 22.1 & 150.5 & 4.73 & 107.3 \\
\hline & 4 & & & & & & \\
\hline & 5 & 7.404 & 53.2 & 32.8 & 142.2 & 4.10 & 99.2 \\
\hline & 6 & & & & & & \\
\hline & 7 & & & & & & \\
\hline & 8 & 7.400 & 33.6 & 20.6 & 138.2 & 4.00 & 105.5 \\
\hline \multirow{7}{*}{4} & & 7.448 & 39.0 & 25.0 & 145.4 & 4.35 & 113.5 \\
\hline & 1 & & & & \multirow{7}{*}{141.8} & \multirow{6}{*}{4.18} & \multirow{6}{*}{110.0} \\
\hline & $\begin{array}{l}2 \\
3\end{array}$ & 7.443 & 40.7 & 27.6 & & & \\
\hline & 4 & & & & & & \\
\hline & 5 & & & & & & \\
\hline & 6 & 7.389 & 45.0 & 26.9 & & & \\
\hline & 8 & 7.392 & 43.0 & 25.8 & & & \\
\hline & & & & & & & \\
\hline
\end{tabular}

IV Acute furosemide loading test...Effects of furosemide upon acid-base balance, serum \& urinary electrolytes and urinary aldosterone excretion. (Fig. 13, Table V)

Furosemide was administered orally in doses of $40 \mathrm{mg}$ after overnight deprivation of water and food. The material comprised nine adult 
patients with congestive heart failure in various condition. And two healthy persons were chosen as normal control.

Indwelling catheter was inserted and urine was collected every thirty minutes after the administration of the drug. Two or three blood specimens were drawn before the test and every one hour thereafter. $\mathrm{pH}, \mathrm{PCO}_{2}$, bicarbonate, serum \& urinary electrolytes and urinary aldosterone were measured.

According to their response to furosemide the patients are divided into four groups.

Two patients of group 1 who had class 4 decompensation and mitral or combined valvu- lar diseases showed a great increase in potassium excretion, but the increase in sodium and water excretion was only slight or moderate.

$\mathrm{pH}$ and $\mathrm{HCO}_{3}^{-}$rose progressively through the experimental period and $\mathrm{PCO}_{2}$ rose in compensating manner from the low normal range to the mean normal level. Serum sodium showed little change and serum potassium remained unchanged even at high level.

Urinary $\mathrm{Na} / \mathrm{K}$ ratio was low and aldosterone excretion was increased before the administration of the drug. Urinary aldosterone reached a maximum in first two hours.

The results in a typical patient (Case 2) are

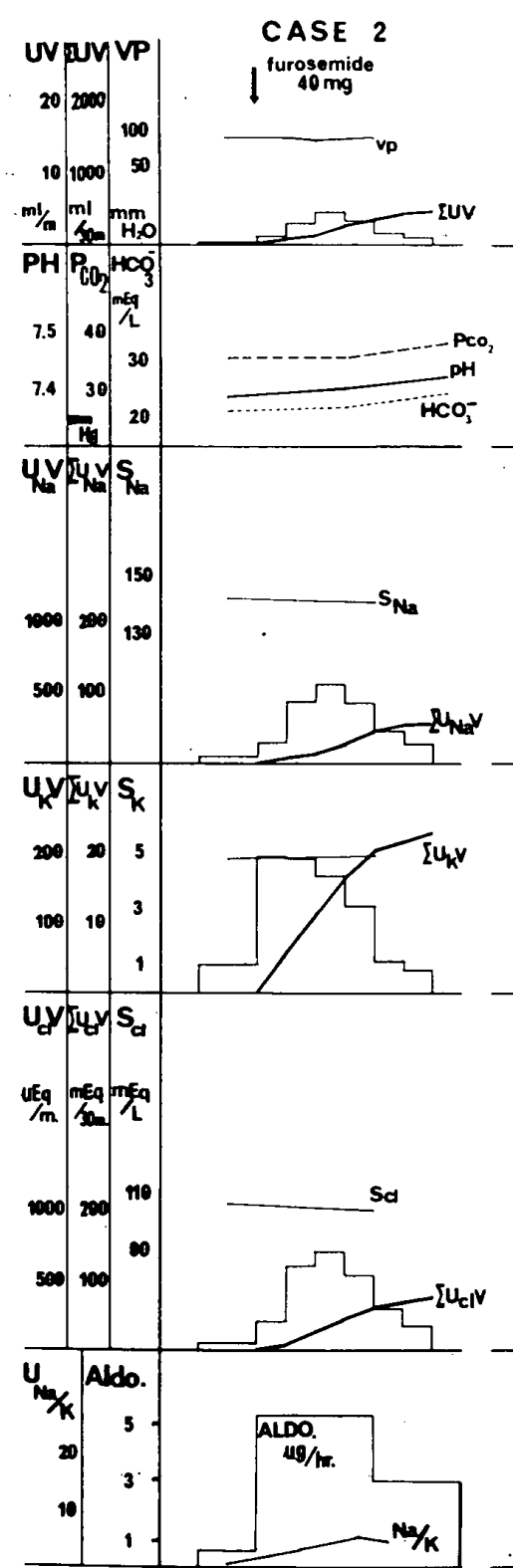

CASE 3
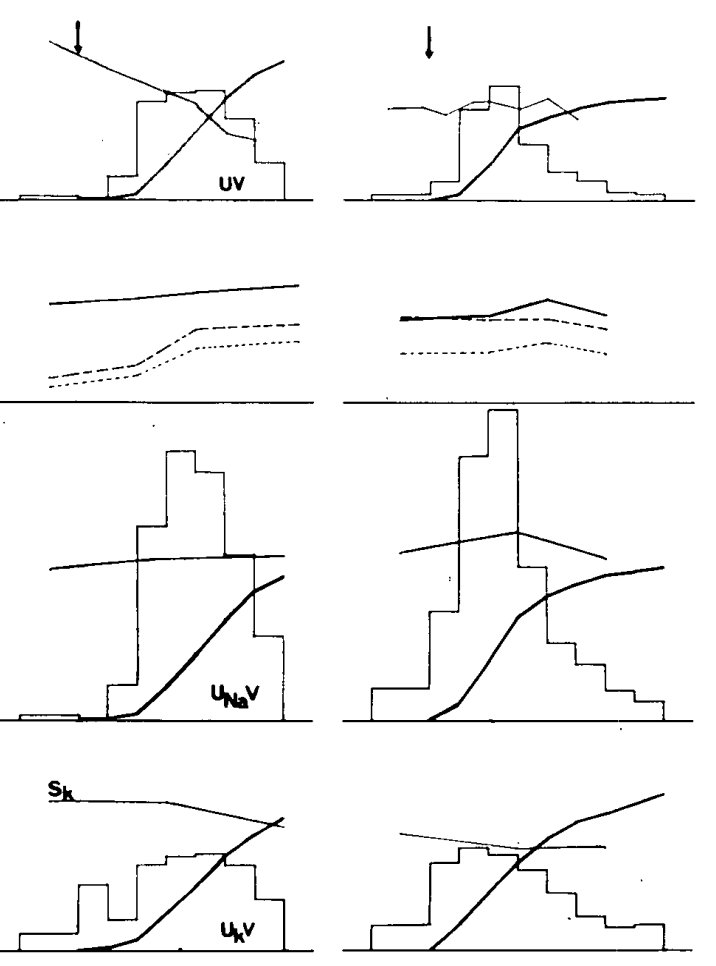

CASE 6

1
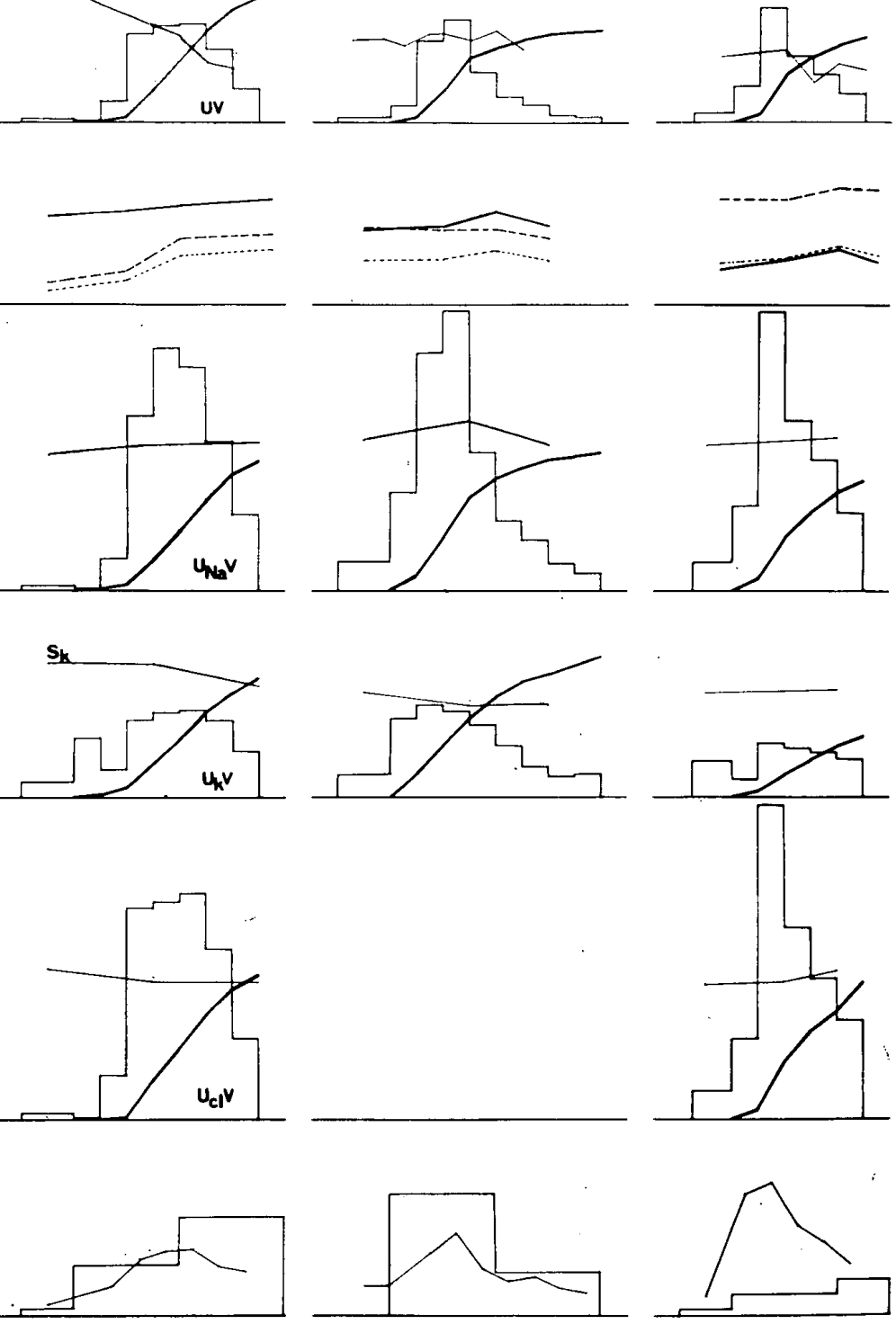

Fig. 13. Effect of furosemide on acid-base balance, serum \& urinary electrolytes and urinary aldosterone excretion.

Japanese Circulation Journal Vol. 33, March 5969 
shown in Fig. 13.

In group 2 there was a great increase in water, sodium and chloride excretion accompanied by a fall in venous pressure, but potassium excretion was relatively low compared with group 1. Serum sodium remained unchanged throughout the experiment, while a considerable fall in potassium occurred.

The alteration in the acid-base balance was much the same as group 1. Urinary excretion of aldosterone increased gradually.

All three patients in this group had class 3 decompensation and mitral or combined valvular diseases. The results were similar in these three subjects and details of Case 3 are shown in Fig. 13.

Two healthy persons in group 3 had a large rise in water, sodium and potassium excretion. Blood $\mathrm{pH}$ rose transiently, then fell to the level similar to that seen before the diuretic was given. $\mathrm{PCO}_{2}$ showed no considerable change.

Serum electrolytes altered slightly, but not significantly.

Urinary aldosterone excretion markedly elevated when the diuretic was given. The results in a typical patient (Case 6) are shown in Fig. 13.

Two patients in group 4 had class 2 decompensation and hypertension. In these cases water and sodium excretion rose, while potassium excretion was less than any other groups.

The alteration in the acid-base balance showed the same pattern as group 3 . Serum electrolytes had only a small increase. Urinary aldosterone level was relatively low before the administration of the drug and elevated gradually with time.

The results in Case 8 are shown in Fig. 13.

\section{Comments}

(1) It has been said that in patients with cardiac dyspnea the $\mathrm{pH}$ is in the majority of cases normal or shifted toward the alkaline side (respiratory alkalosis) ${ }^{4}$ and the oral use of nonmercurial diuretics induce hypokalaemia and metabolic alkalosis ${ }^{5}$.

The author's results are consisted with these observations. But, although homeostatic in regard to $\mathrm{pH}$, the considerable variations in $\mathrm{PCO}_{2}$ and bicarbonate concentration observed in the patients receiving digitalis medication make it difficult to define a given state on the basis of $\mathrm{pH}$ value alone. The alkalosis observed in the diuretic therapy is distinctly of metabolic nature.

Normal or considerably reduced $\mathrm{PCO}_{2}$ in the decompensated cardiac patients has been reported ${ }^{4,6}$. Whereas in this study many patients treated with digitalis alone showed slightly higher than normal $\mathrm{PCO}_{2}$ values. And, as regards $\mathrm{PCO}_{2}$, there is no significant difference between patients with mild and patients with severe condition. The probable explanation of these findings is that the carbon dioxide is removable by the very quick diffusion ${ }^{4}$.

Theoretically an elevated $\mathrm{PCO}_{2}$ would be the mechanism of compensation for metabolic alkalosis. But in the present study the patients treated with diuretics showed normal or even subnormal level in $\mathrm{PCO}_{2}$. This resulted in a superimposition of respiratory alkalosis upon metabolic alkalosis in many cases as shown in Fig. 4.

It has been observed that fixed acids, such as lactic and pyruvic acid, accumulate in advanced stage of heart failure. In a series of experiments the rise in these acids was reported to be associated with reduced $\mathrm{PCO}_{2}{ }^{7}$. This accounts for most of the bicarbonate deficit in the compensation for respiratory alkalosis. However in this study the values of bicarbonate covered a wide range and it was difficult to point out the bicarbonate deficit in terminal cases.

As shown in Fig. 5 there is a linear relationship between $\mathrm{PCO}_{2}$ and bicarbonate concentration, but respiratory compensation for metabolic alkalosis is imcomplete. Theoretically metabolic alkalosis induced by the diuretic therapy is compensated for by respiratory meanselevated $\mathrm{PCO}_{2}$. However clinical literature is inconsistent to this mechanism. The respiratory center activity may be inhibited by an elevated $\mathrm{pH}$, but at the same time the changes in arterial oxygen saturation may limit the respiratory compensation in metabolic alkalosis ${ }^{4,8}$.

(2) An increase in potassium excretion associated with a fall in the serum potassium level is one of the serious problem encountered with diuretic therapy. And it is well known that the oral use of benzothiadiazine group has a 
Table V Effects of Furósemide upon Acid-Base Balance, Serum \& Urinary Electrolytes and

\begin{tabular}{|c|c|c|c|c|c|c|}
\hline Case & $\begin{array}{l}\text { Age } \\
\text { and } \\
\text { Sex }\end{array}$ & Diagnosis & $\begin{array}{l}\text { Urine } \\
\text { Volume } \\
\mathrm{ml} / \mathrm{m} \text {. }\end{array}$ & $p H$ & $\begin{array}{c}\mathrm{P}_{\mathrm{CO}} \\
m m H g\end{array}$ & $\begin{array}{l}\mathrm{HCO}^{-} \\
m E q / L\end{array}$ \\
\hline \multirow{2}{*}{\multicolumn{3}{|c|}{ Group 1}} & 0.3 & 7.433 & 35.8 & 23.6 \\
\hline & & & 1.5 & & & \\
\hline \multirow[t]{7}{*}{1} & $M 26$ & Mitral Valvular Disease & $\begin{array}{l}1.5 \\
3.6\end{array}$ & & & \\
\hline & & & 7.0 & 7.478 & 36.3 & 26.5 \\
\hline & & & 6.8 & & & \\
\hline & & & $\begin{array}{l}4.3 \\
2.5\end{array}$ & & & \\
\hline & & & 2.0 & 7.492 & 36.0 & 27.1 \\
\hline & & & 0.3 & 7.387 & 35.4 & 21.1 \\
\hline & & & 1.2 & & & \\
\hline \multirow[t]{4}{*}{2} & $M 27$ & Combined Valvular Disease & 3.0 & & 25 & \\
\hline & & & $\begin{array}{l}4.7 \\
3.5\end{array}$ & 7.401 & 35.4 & 21.7 \\
\hline & & & $\begin{array}{l}3.5 \\
1.7\end{array}$ & & & \\
\hline & & & 1.2 & 7.420 & 38.0 & 24.3 \\
\hline \multirow[t]{2}{*}{ Group 2} & & & 0.5 & 7.471 & 24.3 & 17.5 \\
\hline & $F \quad 55$ & & 0.2 & & & \\
\hline \multirow[t]{6}{*}{3} & $F 35$ & Mitral Valvular Disease & $\begin{array}{r}3.5 \\
13.6\end{array}$ & 7.483 & 26.5 & 19.6 \\
\hline & & & 15.0 & 7.489 & 32.6 & 24.4 \\
\hline & & & 15.2 & . & & \\
\hline & & & 11.4 & & & \\
\hline & & & 5.5 & 7.506 & 33.3 & 25.5 \\
\hline & & & $\begin{array}{l}2.3 \\
1.8\end{array}$ & 7.425 & 45.0 & 29.1 \\
\hline \multirow[t]{5}{*}{4} & $F 40$ & Combined Valvular Disease & $\begin{array}{r}7.7 \\
12.5\end{array}$ & 7.449 & 46.0 & 31.2 \\
\hline & & & 9.4 & 7.452 & 45.5 & 31.3 \\
\hline & & & $\begin{array}{l}7.5 \\
3.9\end{array}$ & 7.468 & 465 & \\
\hline & & & 0.3 & 7.424 & $\frac{40.5}{35.0}$ & $\frac{32.8}{22.6}$ \\
\hline & & & 1.1 & & & \\
\hline \multirow[t]{4}{*}{5} & $M 36$ & Combined Valvular Disease & 4.8 & 7.427 & 34.5 & 22.4 \\
\hline & & & $\begin{array}{r}13.0 \\
8.4\end{array}$ & 7.466 & 34.5 & 245 \\
\hline & & & 6.2 & 1.700 & (T.J & 24.0 \\
\hline & & & 3.5 & 7.505 & 34.2 & 26.0 \\
\hline Group 3 & & & $\begin{array}{l}0.8 \\
2.7\end{array}$ & 7.443 & 34.9 & 23.5 \\
\hline \multirow[t]{7}{*}{6} & $M 19$ & Control & 12.6 & 7.452 & 34.4 & 23.7 \\
\hline & & & 15.7 & & & \\
\hline & & & $\begin{array}{l}7.7 \\
3.9\end{array}$ & 7.482 & 34.5 & 25.4 \\
\hline & & & 2.5 & & & \\
\hline & & & $\begin{array}{l}1.2 \\
0.8\end{array}$ & 7.453 & 32.7 & 23.5 \\
\hline & & & 0.7 & 7.400 & 35.0 & 21.3 \\
\hline & $M 21$ & Control & 11.2 & & & \\
\hline \multirow{5}{*}{7} & & Contor & $\begin{array}{l}20.0 \\
18.9\end{array}$ & 7.448 & 36.9 & 25.2 \\
\hline & & & 9.1 & & & \\
\hline & & & 3.2 & 7.412 & 38.7 & 23.8 \\
\hline & & & 4.4 & & & \\
\hline & & & 3.2 & & & \\
\hline Group 4 & & & $\begin{array}{l}1.4 \\
5.7\end{array}$ & 7.369 & 40.5 & 23.0 \\
\hline \multirow[t]{5}{*}{8} & $F 45$ & Hypertensive Heart Disease & 17.6 & 7.387 & 40.3 & 23.9 \\
\hline & & & 10.3 & & & \\
\hline & & & 7.3 & 7.410 & 42.6 & 26.6 \\
\hline & & & 4.4 & 7.382 & 42.0 & 24.5 \\
\hline & & & $\begin{array}{l}0.8 \\
2.6\end{array}$ & 7.400 & 32.9 & 20.0 \\
\hline \multirow[t]{4}{*}{9} & $M 62$ & Hypertensive Heart Disease & 21.0 & 7.401 & 32.4 & 20.0 \\
\hline & & & $\begin{array}{l}9.8 \\
6.7\end{array}$ & 7.416 & 36.7 & 23.3 \\
\hline & & & 3.8 & & & \\
\hline & & & 1.4 & 7.400 & 35.0 & 21.3 \\
\hline
\end{tabular}


Urinary Aldosterone Excretion (Urinary Aldosterone was Determind by Kubo \& Nishida)

\begin{tabular}{|c|c|c|c|c|c|c|c|c|c|}
\hline \multicolumn{3}{|c|}{ Serum $m E q / L$} & \multicolumn{3}{|c|}{ Urine $m E q / L$} & \multicolumn{3}{|c|}{ Urine $m E q / 30 m$} & \multirow{2}{*}{$\begin{array}{l}\text { Urinary } \\
\text { Aldosterone } \\
\mu \mathrm{g} / \mathrm{hr}\end{array}$} \\
\hline $\mathrm{Na}$ & $K$ & $\mathrm{Cl}$ & $\overline{N a}$ & $K$ & $C l$ & $N a$ & $K$ & $C l$ & \\
\hline \multirow[t]{2}{*}{148.3} & 4.92 & 120.0 & 56.0 & 144.4 & 144.2 & 1.1 & 2.7 & 2.7 & \\
\hline & & & 130.0 & 30.0 & 166.5 & 5.7 & 1.3 & 7.3 & \\
\hline \multirow[t]{2}{*}{146.9} & 5.23 & 115.2 & 140.0 & 38.0 & 179.0 & 6.1 & 1.7 & 7.8 & \\
\hline & & & 145.0 & 30.0 & 175.1 & 15.8 & 3.3 & 19.1 & \\
\hline \multirow[t]{2}{*}{144.7} & 5.43 & 111.8 & 140.0 & 11.8 & 157.4 & 29.6 & 2.5 & 33.3 & \\
\hline & & & 140.0 & 22.0 & 156.8 & 28.6 & 4.5 & 32.0 & \\
\hline \multirow[t]{2}{*}{147.3} & 5.47 & 117.3 & 140.0 & 29.0 & 159.5 & 17.9 & 3.7 & 20.3 & \\
\hline & & & 140.0 & 35.7 & 179.1 & 10.7 & 2.7 & 13.6 & \\
\hline 147.5 & 5.47 & 115.3 & 140.0 & 37.0 & 178.3 & 8.2 & 2.2 & 10.5 & \\
\hline \multirow[t]{5}{*}{142.4} & 4.69 & 105.1 & 117.0 & 158.8 & 163.4 & & & & 0.58 \\
\hline & & & 117.0 & 158.8 & 163.4 & 4.1 & 5.6 & 5.7 & \\
\hline & & - & 143.0 & 66.0 & 191.0 & 13.0 & 6.0 & 17.4 & \\
\hline & & & 117.0 & 34.5 & 145.0 & 16.5 & 4.9 & 20.4 & 5.23 \\
\hline & & & 117.0 & 34.5 & 145.0 & 12.2 & 3.6 & 15.1 & 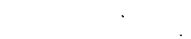 \\
\hline 141.4 & 4.78 & 102.6 & 133.0 & 25.0 & 153.0 & 6.8 & 1.3 & 7.8 & \\
\hline & & & 120.0 & 28.0 & 138.4 & 4.2 & 1.6 & 4.8 & 3.03 \\
\hline 137.3 & 5.23 & 112.9 & 103.0 & 45.8 & 93.6 & & & & 0.30 \\
\hline & & & 103.0 & 45.8 & 93.6 & 0.5 & 0.2 & 0.5 & \\
\hline & & & 74.0 & 11.6 & 97.4 & 7.8 & 1.2 & 10.2 & \\
\hline 141.0 & 5.19 & 108.1 & 99.5 & 8.7 & 119.1 & 40.7 & 3.6 & 48.6 & 1.99 \\
\hline & & & 106.0 & 8.6 & 118.2 & 46.4 & 3.9 & 53.1 & \\
\hline & & & 113.0 & 8.6 & 119.1 & 51.4 & 3.9 & 54.2 & \\
\hline & & & 100.0 & 10.4 & 116.3 & 34.3 & 3.6 & 40.0 & \\
\hline 142.0 & 4.33 & 108.1 & 106.0 & 12.4 & 116.3 & 17.5 & 2.1 & 19.2 & 3.82 \\
\hline 139.6 & 4.03 & 110.5 & 110.0 & 28.0 & 101.8 & & & & \\
\hline & & & 113.0 & 23.0 & 119.0 & 6.1 & 1.3 & 6.5 & \\
\hline 145.4 & 4.14 & 99.2 & 126.0 & 14.5 & 137.5 & 29.1 & 3.4 & 31.8 & \\
\hline & & & 126.0 & 12.4 & 153.4 & 45.6 & 4.5 & 55.5 & \\
\hline 140.4 & 3.64 & 90.2 & 140.0 & 14.5 & 154.5 & 39.6 & 4.1 & 43.7 & \\
\hline & & & 150.0 & 15.4 & 158.0 & 33.7 & 3.5 & 35.5 & \\
\hline 142.8 & 3.62 & 90.2 & 165.0 & 20.2 & 172.3 & 19.3 & 2.4 & 20.1 & \\
\hline 142.4 & 4.30 & 101.0 & 113.0 & 94.0 & 150.9 & & & & \\
\hline & & & 165.0 & 62.6 & 186.0 & 5.3 & 2.0 & 6.0 & \\
\hline & & & 143.0 & 23.0 & 152.2 & 20.6 & 3.3 & 21.9 & \\
\hline & & & 137.0 & 14.6 & 143.1 & 53.6 & 5.7 & 55.0 & \\
\hline 142.0 & 4.32 & 102.5 & 137.0 & 16.4 & 146.9 & 34.5 & 4.1 & 37.0 & \\
\hline & & & 140.0 & 19.4 & 146.9 & 26.0 & 3.6 & 27.3 & \\
\hline 144.0 & 4.22 & 100.8 & 133.0 & 25.2 & 143.1 & 14.0 & 2.7 & 15.0 & \\
\hline 143.0 & 4.14 & & 280.0 & 45.0 & & & & & \\
\hline & & & 278.0 & 45.4 & & 22.2 & 3.6 & & \\
\hline & & & 145.0 & 11.4 & & 54.7 & 4.3 & & \\
\hline 150.0 & 3.58 & & 137.0 & 8.6 & & 64.7 & 4.1 & & 4.73 \\
\hline & & & 137.0 & 14.6 & & 31.6 & 3.4 & & \\
\hline & & & 137.0 & 20.0 & & 15.9 & 2.3 & & \\
\hline & & & 148.0 & 19.4 & & 11.2 & 1.5 & & 1.68 \\
\hline 140.0 & 3.64 & & 157.1 & 28.2 & & 5.5 & 1.0 & & \\
\hline & & & 162.0 & 42.4 & & 4.1 & 1.1 & & \\
\hline 144.8 & 4.13 & & 262.2 & 67.5 & & & & & \\
\hline & & & 145.0 & 13.2 & & 48.9 & 4.5 & & \\
\hline & & & 131.0 & 9.8 & & 77.3 & 5.8 & & \\
\hline 143.9 & 4.64 & & 133.0 & 10.0 & & 77.5 & 5.7 & & \\
\hline & & & 130.5 & 17.3 & & 35.8 & 4.7 & & \\
\hline 142.5 & 4.00 & & 121.7 & 24.0 & & 11.8 & 2.3 & & \\
\hline & & & 134.0 & 21.3 & & 17.8 & 2.8 & & \\
\hline & & & 139.2 & 22.6 & & 13.5 & 2.2 & & \\
\hline 149.4 & 4.00 & 104.1 & 152.5 & 39.2 & 165.1 & $6 . \overline{3}$ & 1.7 & 7.3 & 0.29 \\
\hline & & & 113.0 & 4.8 & 112.2 & 19.2 & 0.8 & 19.1 & \\
\hline 142.6 & 4.14 & 107.4 & 122.5 & 4.8 & 139.0 & 64.7 & 2.5 & 73.4 & \\
\hline & & & 126.0 & 7.3 & 144.0 & 39.1 & 2.3 & 44.6 & 0.84 \\
\hline 143.7 & 4.16 & 113.2 & 136.0 & 9.4 & 149.2 & 29.9 & 2.1 & 32.8 & \\
\hline & & & 136.0 & 13.6 & 154.0 & 18.0 & 1.8 & 20.3 & 1.40 \\
\hline 138.4 & 3.60 & 119.0 & 178.0 & 10.6 & 194.0 & 4.5 & 0.3 & 4.9 & \\
\hline & & & 136.0 & 8.6 & 144.5 & 10.7 & 0.7 & 11.4 & . \\
\hline & & & 139.0 & 5.9 & 151.5 & 88.1 & 3.8 & 96.0 & \\
\hline 143.0 & 3.66 & 109.0 & 150.0 & 9.6 & 162.5 & 44.1 & 2.8 & 47.8 & \\
\hline & & & 139.0 & 15.4 & 168.0 & 27.8 & 3.1 & 33.6 & \\
\hline & & & 150.0 & 20.2 & 163.0 & 17.3 & 2.3 & 18.8 & \\
\hline 146.0 & 3.54 & 100.9 & 136.0 & 17.4 & 181.5 & 5.7 & 0.7 & 7.6 & \\
\hline
\end{tabular}

Japanese Circulation Journal Vol. 33, March 1969 
tendency to induce metabolic alkalosis and considerable electrolytes disturbance. The author also refered it in the case reports. Benzothiadiazine diuretics have two effects upon the potassium excretion. Firstly, they block the proximal reabsorption of potassium and more sodium fall into available for exchange with potassium and hydrogen ions in the distal tubule ${ }^{9,10}$.

Secondly, they are weak cărbonnic anhydrase inhibitors and promote potassium excretion by the kidney. This will result in hypokalaemia and alkalosis.

However there is no information available of the definite correlation between the extent of potassium deficit and the severity of alkalosis. HoLIDAy reported that the animals made alkalotic had excreted large amounts of potassium ${ }^{11}$. And some workers suggested conversely that withdrawal-of potassium would cause-metabolic alkalosis ${ }^{12,13}$. On the other hand it is said that in alkalosis, either metabolic or respiratory, serum potassium tends to be lower ${ }^{14}$.

In this study, as shown in Fig. 6, no considerable correlation was found between $\mathrm{pH}$ and serum potassium in general. But, as shown in Fig. $11 \&$ Table III, changes in $\mathrm{pH}$ and serum potassium were evident after one week's diuretic therapy, although Hutcheon \& TAKASU have reported no significant changes in the short-term experiment ${ }^{15}$.

It has been shown repeatedly that the use of an aldosterone antagonist in combination with benzothiadiazine diuretics tends to restore the pattern which is kaliuretic rather than natriuretic to normal. The administration of aldosterone antagonist spironolactone results in an increase in urinary sodium and chloride excretion accompanied by a decrease in urinary potassium, hydrogen and ammonium ions ${ }^{16,17}$. Spironolactone seems to block the action of aldosterone at peripheral site and does not block the secretion itself ${ }^{16}$. The explanation why the supplement of spironolactone prevents the metabolic alkalosis occurring with benzothiadiazine group must be that spironolactone inhibits the renal excretion of hydrogen ion so markedly ${ }^{16,18,19}$.

Many patients with congestive heart failure have been found to be secreting abnormally large quantities of aldosterone $\mathrm{e}^{20,21}$, either as a result of their cardiac failure or in response to the dehydrating therapy, though in our clinic there seems to be no discernible correlation between urinary excretion of aldosterone and the degree of decompensation ${ }^{21}$.

In the above mentioned case reports, Case 2 $\& 3$ had been possibly in the state of hyperaldosteronism. And with prolonged treatment spironolactone-induced sodium loss would have intensified the stimulus to aldosterone secretion further. The development of metabolic alkalosis and preventive action of spironolactone which have been observed in these cases are concurrent with before-mentioned reports.

In Case 3 shown in Fig. 10, after withdrawal of spironolactone a marked increase in $\mathrm{pH}$ and bicarbonate concentration occurred transiently. This phenomenon seems to have something to do with an acute increase in urinary excretion of aldosterone - so-called "rebound phenomenon". We have observed this phenomenon in almost all cases treated with spironolactone ${ }^{22}$.

(3) In acute digitalisation patients generally released from signs of decompensation within three or four days. $\mathrm{PCO}_{2}$ accompanied with an increase in bicarbonate concentration showed the tendency to rise for several days. So the fall in $\mathrm{pH}$ is considerable to be of respiratory nature. These changes may be insignificant, but it is interesting that all four patients had the same tendency during their recovering process:

In patients with cardiac decompensation reduced oxygen saturation because of the presence of pulmonary congestion contribute to increase the ventilation. So it is conceivable that the rise in $\mathrm{PCO}_{2}$ is partially due to the oxygen therapy which increases the arterial oxygen saturation independent on $\mathrm{PcO}_{2}{ }^{4}$.

(4) The aim of acute furosemide loading test is to compare the various types of response in congestive heart failure.

In group 1, patients had been found resistant to furosemide. Water and sodium excretion showed only a small increase, while potassium was greatly excreted. This type of response had been also reported by others ${ }^{23}$.

The changes found in group 1 seem to be related to the activity of aldosterone. And in 
these cases small loss of sodium, not contraction of body water, played an important role to induce the change in urinary aldosterone excretion $^{24}$.

Edmonds \& Wilson suggested that in generalized oedema state a natriuresis effected in the proximal tubule was converted to a kaliuresis by subsequent aldosterone-conditioned exchange of sodium for potassium in the distal part of each nephron ${ }^{25}$. However both patients of this group showed hyperkalaemia irrespective of secondary hyperaldosteronism and high excretion rate of potassium. It needs further experimental analysis for the final conclusion in this area.

In group 2, furosemide produced natriuresis and the potassium loss was great. But the circulating plasma volume did not change considerably ${ }^{24}$. This was probably due to a shift of oedema fluid from interstitial compartment to the vascular space. And progressive increase in urinary aldosterone excretion took place with increasing sodium loss. Some workers have found the increase in urinary aldosterone after diuretics in normals and oedematic patients to be a transient one $\mathrm{e}^{26}$, but in this study aldosterone output was prolonged in spite of the short-lived natriuresis.

There are two probable explanations of the swing toward alkalinity in this group. All three patients showed the considerable fall in serum potassium during the diuresis. The fall in serum potassium reflects a renal loss of potassium which does not merely reduce the extracellular potassium but gives an even more reduction of the potassium content in the cells ${ }^{10,27,28,29}$. And in the face of an intracellular potassium deficit, hydrogen ion which replaced a part of potassium ion in the cell ${ }^{29,30}$ would be excreted preferentially over potassium ion in exchange for sodium ion $^{31}$. In fact, group 2 showed smaller excretion rate of potassium than group 1 in spite of their effective natriuresis. One more explanation of these hypokalaemic alkalosis is that sodium bicarbonate contained in the oedematous fraction of the extracellular fluid would be excreted after furosemide was given ${ }^{23}$. But other workers reported unchanged net acid excretion in the face of an increased bicarbonate excretion ${ }^{19}$. This may be taken as evidence of an increased excretion of hydrogen ions.

In group 3, when furosemide was given, sodium and potassium excretion were greater than any other groups and serum potassium was slightly depressed. But the change in acidbase balance was transient and never gross as group 4. On the other hand the increase in urinary aldosterone excretion during the diuresis was striking, though seemed to be a transient one. This marked change seems to be induced by the decrease in circulating blood volume rather than urinary sodium loss ${ }^{24}$.

In group 4 , the change in acid-base balance was never gross and transient, too. Differed from other groups, both subjects excreted distinctly more sodium than potassium. And despite over-night dehydration and considerable urinary sodium excretion, the change in aldosterone output was modest and of questionable significant. On this subject WoLFF and others reported unchanged urinary aldosterone level in the left-sided heart failure ${ }^{20,21}$.

All four groups can be classified again into two groups according to whether their swing toward alkalinity is progressive or transient. And this change seems to have significant correlation with continuous hypersecretion of aldosterone. This emphasizes over again the importance of aldosterone in the aetiology of alkalosis.

Many studies have demonstrated that adrenal steriods and potassium excretion play an important part in acid-base regulation ${ }^{10,11,32}$ and respiratory compensation for metabolic alkalosis is minimal ${ }^{8}$. It is well known that hypokalaemic alkalosis is associated with primary aldosteronism and Cushing's Syndrom ${ }^{33}$. But definite relationship between metabolic alkalosis, adrenal steroids and potassium loss has not been established ${ }^{34,35,36,37}$.

In the present study continuous alkaline side, elevated urinary aldosterone excretion and increased urinary potassium excretion were similarly observed in both group $1 \& 2$. But in group 3 transient acid-base balance disturbance and great increase in urinary potassium excretion were found concurrently. So it appears that the serum alkalinity can not be attributed to the potassium loss alone $\mathrm{e}^{10,11,34}$. And it is possible that in healthy person hormonal con- 
trol is transient and effective and other regulating systems are also well established against exogeneous disturbing factors.

\section{SUMMARY}

(1) $\mathrm{pH}$ in the patients with cardiac failure who had received digitalis was normal and in a few cases shifted toward the alkaline side. Whereas the patients treated with digitalis and benzothiadiazine diuretics showed the increase in $\mathrm{pH}$ (metabolic alkalosis or mixed metabolic and respiratory alkalosis).

(2) Some patients with digitalis showed a slight rise in $\mathrm{PCO}_{2}$, but there was no significant correlation between $\mathrm{PCO}_{2}$ and the degree of the cardiac decompensation.

Respiratory compensation for metabolic alkalosis was incomplete.

(3) The changes in $\mathrm{pH}$ and serum potassium were evident after one week's diuretic therapy. But, in general, no considerable correlation was found between $\mathrm{pH}$ and serum potassium.

(4) All the patients showed normal or nearnormal $\mathrm{Po}_{2}$.

(5) Long-term treatment with trichloromethiazide resulted in the development of metabolic alkalosis.

The addition of spironolactone prevented the thiazide-induced metabolic alkalosis.

An increase in urinary excretion of aldosterone after withdrawal of spironolactone seems to have a close relationship with a marked rise in blood $\mathrm{pH}$.

(6) In acute digitalisation patients showed gradual elevation in $\mathrm{PCO}_{2}$ concurrent with the recovery from cardiac decompensation.

(7) The results in the furosemide loading test suggest that a progressive rise in $\mathrm{pH}$ has a significant correlation with continuous hy persecrection of aldosterone.

And metabolic alkalosis seems not to be attributed to the potassium loss only.

\section{Acknowledgement}

The author wishes to thank Professor M. Takayasu and Adjunct Professor Y. Nohara for their helpful advice in this study.

Thanks are also tendered to Dr. T. Nakano for his technical guidance.

This report is the thesis for the degree of Kyoto University.

\section{REFERENCES}

1. Austin, W. H., et al.: Solubility of Carbon Dioxide in Serum from $15^{\circ}$ to $38^{\circ} \mathrm{C}$, J.Appl. Physiol. 18: 301 , 1963.

2. Leibman, J. \& Edolman, I.: Interrelationship of Plasma Potassium Concentration, Plasma Sodium Concentration, Arterial $\mathrm{pH}$ and Total. Exchangeable Potassium, J. Clin. Invest. 38: 2176, 1959.

3. Burnell, J. M., et al.: The Effect in Humans of Extracellular $\mathrm{pH}$ Change on the Relationship between Serum Potassium Concentration and Intracellular Potassium, J. Clin. Invest. 35: 935, 1956.

4. Moltke, E. \& Worning, H. : Studies on the Hydrogen Ion Concentration, Oxygen Saturation and Carbonic Dioxide Tension of the Arterial Blood in Patients with Cardiac Dyspnoea, Acta Med. Scand., 160: 397, 1958.

5. ACHOR, W. P., et al.: Treatment of Hypertension with Benzydroflumethiazide as the Sole Antihypertensive Agent, New Eng. J. Med. 265: 457, 1961.

6. Novak, P., et al.: Studies of the Cerebral Circulation and Metabolism in Congestive Heart Failure, Circulation $7:$ 724, 1953.

7. Eisenholz, A. et al.: Primary Hypocapnia: A Cause of Metabolic Acidosis, J. Appl. Physiol. 17: 283, 1962.

8. Roberts, K., et al.: Evaluation of Respiratory Compensation in Metabolic Alkalosis, J.Clin. Invest. $35: 261,1956$.

9. Kessler, R. H., et al.: Localization of Action of Chlorothiazide in the Nephron of the Dog, Amer. $J$. Physiol. 196: 1346, 1959.

10. VANDER, A. J., et al.: Localization of the Site of Action of Chlorothiazide by Stop-Flow Analysis, $J$. Pharmacol. Exp. Ther. 125: 19, 1959.

11. Holiday, M.: Acute Metabolic Alkalosis: Its Effect on Potassium and Acid Excretion, J. Clin. Invest. 34: 428, 1955.

12. Womersley, R. \& Darragh, J.: Potassium and Sodium Restriction in the Normal Human, J.Clin. Invest. 34: 456, 1955.

13. Cooke, R., et al.: The Role of Potassium in the Prevention of Alkalosis, Amer. J. Med. 17: 180, 1954.

14. Elkinton, J. R., et al.: Intracellular Cation Exchange in Metabolic Alkalosis, J. Clin. Invest. 30: $369,1951$.

15. Hutcheon, D., \& Takasu, T.: The Diuretic Action of Trichloromethiazide in Patients with Congestive Heart Failure, Clin. Pharmacol. Ther. 1 : 444, 1960.

16. Lidde, G. W.: Aldosterone Antagonists, $A . M$. $A$. Arch. Intern. Med. 102: 998, 1958.

17. Edmonds, C. J.: An Aldosterone Antagonist and Diuretics in the Treatment of Chronic Oedema and Ascites, Lancet 1: 509, 1960.

18. Olesen, K., \& Sande, E.: Hypokalaemia, Hypochloraemia, and Baseosis in Long-term Treatment of Oedematous Heart Failure with Benzothiadiazine Diureticts: Effect of Spironolactone, Acta Med. Scan. 172: 703, 1962.

19. SAnde, E., \& Oleses, K.: Hypokalaemia, Hypochloraemia, and Baseosis in Long-term Treatment of Oedematous Heart Failure with Benzothiadia- 
zine Diuretics: Incidence and Pathophysiology, Acta Med. Scand. 172: 691, 1962.

20. WolfF, H. P., et al.: Hyperaldosteronism in Heart Disease, Lencet 2: 63, 1957.

21. Kuво, S.: to be published.

22. Saimyoji, H., et al. : Clinical Studies on the WaterElectrolytes Regulation Mechanism in Chronic Congestive Heart Failure, Proceedings of the Third Asian-Pacific Congress of Cardiology pp. 1386-1.391, 1964.

23. Stewart, W. K., \& Constable, L.: The Diuretic Response to Hygroton, Mersalyl, and Aldactone, Lancet 1: 523, 1961.

24. Takayasu, M., et al.: Clinical Studies on the Water-Electrolyte Regulation Mechanism in Chronic Congestive Heart Failure (to be published)

25. Edmonds, C. J., \& Wilson, G. M.: The Action of Hydroflumethiazide in Relation to Adrenal Steroids and Potassium Loss, Lancet 1: 505, 1960.

26. Truniger, B., und Siegenthalen, W. : Aldosterone und Diuretica, Klin. Wschr. 38: 385, 1960.

27. Hollander, W., et al.: The Role of Diuretics in the Management of Hypertension, Ann. N.Y. Acad. Sci. 88: 975, 1960.

28. Mudge, G., \& Vislocky, K.: Electrolyte Changes in Human Striated Muscle in Acidosis and Alkalosis, J. Clin. Invest. 28 : 482, 1949.

29. Gardner, L., et al. : Effect of Potassium Deficiency on Carbon Dioxide, Cation, and Phosphate Content of Muscle, J. Gen. Physiol. 36: 153, 1953.
30. Orloff, J., et al.: The Effect of Potassium in Nephrectomized Rats with. Hypokalaemic Alkalosis, J. Clin. Invest. 32: 538, 1953.

31. BERLINER, R., et al.: Relationship between Acidification of the Urine and Potassium Metabolism, Amer. J. Med. 11: 274, 1951.

32. Liddle, G. W.: "Summarization of the Effect of Hormones on Water and Electrolyte Metabolism" in Williams, R. H.: Textbook of Endocrinology, ed, 3, New York W. B. Saunders \& Co., 1962, pp. 10771078.

33. Christy, N., \& Laragh, J. : Pathogenesis of Hypokalaemic Alkalosis in Cushing's Syndrome, New Eng. J. Med. 265: 1083, 1961.

34. Grollman, A., \& Gamble, J., Jr.: Metabolic Alkalosis: A Specific Effect of Adrenocortical Hormones, Amer. J. Physiol. 196: 135, 1959.

35. Atkins, E., \& Schwartz, W.: Factors Govering Correction of the Alkalosis Associated with Potassium Deficiency: The Critical Role of Chloride in the Recovery Process, J. Clin, Invest. 41: 218, 1962.

36. Sande, E., \& Olesen, K.: Hypokalaemia, Hypochloraemia, and Baseosis in Long-term Treatment of Oedematous Heart Failure with Benzothiadiazine Diuretics: Prophylactic Value of Potassium Chloride, Acla Med. Scan. 172: 699, 1962.

37. Simmons, D. H., \& Avedon, M.: Acid-Base Alterations and Plasma Potassium Concentration, Amer. J. Physiol. 197 : 319, 1959. 